\title{
Attracting unwanted attention: generalization of behavioural adaptation to an invasive predator carries costs
}

Christopher J. Thawley*a and Tracy Langkilde ${ }^{\mathrm{a}, 2}$ 


\section{ABSTRACT}

2 Behavioural responses of animals to environmental cues are often governed by general "rules

3 of thumb". Animals that face novel conditions as a result of global environmental change may

4 alter these behavioural rules to persist. However, adaptation of generalized rules to novel

5 pressures may cause a species to be maladapted to original conditions (e.g., predators) that

6 remain in its environment. Invasive red imported fire ants (Solenopsis invicta) are novel

7 predators of eastern fence lizards (Sceloporus undulatus). Lizards from fire ant-invaded sites

8 break crypsis to flee from fire ants at higher frequencies than fire ant naïve lizards. This shift

9 promotes survival of attacks by these invasive ants but could result in attacks by native visual

10 predators. Generalization of this increase in antipredator behaviour to native species could

11 further increase this cost. We tested whether lizards' increased propensity to flee from fire ants

12 is generalized to native ants and a predatory bird. We found that increased behavioural

13 responsiveness to fire ants was generalized to two native ants but not to a perceived avian

14 predator. We also found that lizards from populations invaded by fire ants had higher

15 prevalence of injuries in the field, likely indicating greater attempted predation. We propose

16 that generalized anti-ant behaviour may improve survival in the presence of fire ants but

17 increase attacks by native visual predators. This study suggests that generalized rules can be

18 maladaptive under novel conditions and highlights the challenges of assessing the costs and

19 benefits of adaptations to rapid environmental change.

21 Key-words antipredator response, invasive species, maladaptation, predator recognition, trade-

22 off, crypsis, behavioural rule 
The complex suites of behaviours used by many organisms are often a product of both

24 specific and general underlying rules. For example, individuals can use behavioural rules to

25 decide to treat as a potential mate or predator anything that smells, tastes, appears, or behaves

26 in a specific way (Jennions \& Petrie, 1997; Frid \& Dill, 2002). General rules may allow responses

27 to generic cues such as looming shapes (Carlile, Peters, \& Evans, 2006) or objects of a particular

28 color, texture (Gwynne \& Rentz, 1983), or size (Arak, 1983; Marco, Kiesecker, Chivers, \&

29 Blaustein, 1998). Precise rules may require a particular combination of multiple, specific cues to

30 elicit a behavioural response (Hankiston \& Morris, 2003).

31 Behavioural rules are generally only as complex as required to be adaptive within an

32 environment (Schlaepfer, Runge, \& Sherman, 2002), and general rules may evolve more quickly

33 and easily than complex ones (Orr, 2000). While relying on specific rules reduces the risk of

34 making errors, general rules for behaviour are valuable as they allow for responses to many

35 different environmental cues and obviate the costs of discriminating specific cues (Sih, 2013;

36 Carthey \& Banks, 2014). These rules are strategies that work on aggregate over multiple

37 iterations in diverse or uncertain situations (Lima \& Dill, 1990), and their use may lead to more

38 predictable outcomes in variable environments (Heiner, 1983).

39 However, reliance on general rules can incur costs as the chances of responding

40 inappropriately to cues are higher than if rules are more specific. For example, males with

41 indiscriminate mate choice could waste time and energy, and lose mating opportunities, by

42 attempting to mate with unsuitable partners or objects (e.g., anurans mating with dead or

43 heterospecific individuals, or shoes; Meshaka, 1996), and parents caring for any offspring they 
44 encounter could bear the costs of raising unrelated individuals (e.g., hosts of nest parasites;

45 Payne, 1998).

46 The fitness consequences of generalized behavioural responses are a focus of much

47 recent research and theory, especially in the context of rapid environmental change

48 (Schlaepfer, Sherman, Blossey, \& Runge, 2005; Sih, 2013, Carthey \& Banks, 2014). Novel or

49 rapidly changing selective regimes can result in maladaptation or evolutionary traps (Crespi,

50 2000; Schlaepfer, Sherman, \& Runge, 2010), including in response to environmental change

51 (Bradley St. Clair \& Howe, 2007, Sinervo et al., 2010; Kerby \& Post, 2013). Indeed, general rules

52 of behaviour can be especially costly when the environment changes and organisms apply these

53 rules in the wrong context. For example, an organism could suffer reduced fitness by

54 attempting to mate with an invasive species (Gröning \& Hochkirch, 2008) or man-made object

55 that fulfils their general rules for mate identification (Gwynne \& Rentz, 1983). Generalized

56 responses to novel predators and prey can also reduce survival. For instance, generalist

57 predators preying upon toxic invasive Cane Toads (Rhinella marina) can be poisoned (Shine,

58 2010), and New Zealand mudsnails react to invasive crayfish by burrowing, an ineffective

59 defence against these novel predators (Sih, 2013). Accelerating global environmental change

60 provides an excellent opportunity to examine the costs and benefits of generalized behaviours,

61 especially in the case of adaptive responses to the novel conditions (Sinervo et al., 2010;

62 Carthey \& Banks, 2014).

63 To fully determine the consequences of behavioural adaptations to novel selective

64 pressures, we need to understand: 
65 1) Behavioural change. How behaviour has changed in response to novel environmental

66 conditions.

67 2) Specificity of change. If behavioural changes are specific to novel environmental conditions

68 (e.g., to an introduced predator only), or generalized to similar stimuli (e.g., to other

69 ecologically similar species) or even more broadly (e.g., to all potential predators).

70 3) Costs of change. If behavioural changes are either beneficial or costly (e.g., cause decreased

71 survival or wasted time and energy), as we might expect if changes in behaviour are generalized

72 across multiple situations/species.

73 Antipredator behaviour is an excellent system with which to address these issues. These

74 behaviours are expected to be under strong selection in many situations including the

75 introduction of novel predators (Abrams, 2000). For example, native tadpoles (Lithobates

76 aurora) that are naïve to invasive predatory bullfrogs (Lithobates catesbeiana) suffer high

77 mortality (Kiesecker \& Blaustein, 1997). However, tadpoles from populations that have been

78 exposed to this novel selection have adapted in less than 60 years by reducing activity levels to

79 avoid predation (Kiesecker \& Blaustein, 1997).

80 Even when successful, antipredator behaviour is known to carry a variety of costs,

81 including higher energy usage, lower foraging rates/opportunities, and reduced ability to

82 defend territories (Lima \& Dill, 1990; Martín, Luque-Larena, \& Lopez, 2009). If adaptations to

83 novel predators alter general antipredator behavioural rules, applying these rules to

84 interactions with native predators may incur these costs and lower fitness. When a trade-off

85 between the costs and benefits of novel behaviour is not optimally balanced, maladaptation, 
86 potentially as an ecological or evolutionary trap, may occur (Schlaepfer et al., 2002; Schlaepfer

87 et al., 2005; Sih 2013).

88 Here, we use a system involving change in antipredator behaviour of native lizards

89 (Sceloporus undulatus) in response to invasive, predatory red imported fire ants (Solenopsis

90 invicta; hereafter fire ants) to address the three issues highlighted above:

91 1) Behavioural change. Antipredator behaviour of this lizard has changed in response to

92 invasion by fire ants: fence lizard populations largely switch from relying on crypsis (an adaptive

93 response to predominantly visual predators; Martín et al., 2009) to flight during encounters

94 with these predatory invaders (Langkilde, 2009a).

95 2) Specificity of change. In this study, we use staged encounters to test if this shift in

96 behavioural response to fire ants is generalized to two native ant species that are prey for fence

97 lizards, and to a native avian predator, revealing the specificity of this behavioural adaptation.

98 3) Costs of change. We also look for evidence of greater prevalence of injuries in lizards from

99 populations showing increased responsiveness to fire ants, a potential fitness cost of this

100 behavioural change.

101

102 METHODS

103 Study System

104 Fire ants are native to South America and were introduced to Mobile, AL in the

105 southeastern Unites States in the 1930's (Tschinkel, 2006). This species has since spread

106 throughout the southeastern U.S. where it overlaps with the range of the eastern fence lizard

107 (Conant \& Collins, 1998). While fence lizards and fire ants both favor disturbed, edge habitats 
108 (Langkilde, 2009b) and interact frequently in natural environments (Freidenfelds, Robbins, \&

109 Langkilde, 2012), fence lizards do not change their habitat use in the presence of fire ants

110 (Langkilde, 2009b). Fire ants recruit in high numbers to potential prey, including small

111 vertebrates (Allen, Demarais, \& Lutz., 1994; Wojcik et al., 2001), and as few as 12 attacking ants

112 can paralyze and kill an adult fence lizard (Langkilde, 2009a). Ants make up a significant portion

113 of the diet of fence lizards (DeMarco, Drenner, \& Ferguson, 1985; Mobley, 1998), and lizards

114 can be envenomed when consuming fire ants (Langkilde \& Freidenfelds, 2010), which become

115 the numerically dominant ant within invaded areas (Vinson, 1994; Epperson \& Allen, 2010).

$116 \quad$ Fence lizards have adapted morphologically and behaviourally to invasive fire ants

117 within 70 years ( $\approx 40$ generations; Langkilde, 2009a). These lizards are well-camouflaged and

118 generally rely on crypsis to defend against visual predators including lizards, snakes, and birds

119 of prey (Cooper, Burghardt, \& Brown, 2000; Jensen, Camp, Gibbons, \& Elliott, 2008). While

120 lizards from populations not yet invaded by fire ants (uninvaded sites) flee from $\approx 50 \%$ of fire

121 ant attacks, lizards from populations invaded by fire ants for long periods of time (invaded sites)

122 flee at a higher rate ( $\approx 85 \%$; Langkilde, $2009 a)$. These flee behaviours reduce contact with and

123 envenomation by attacking fire ants (Freidenfelds et al., 2012).

124 Study Sites and Animals

125 We captured lizards from six study sites in the southeastern United States: (1) Solon

126 Dixon Forestry Education Center, Escambia Co., Alabama $\left(31.16^{\circ},-86.70^{\circ}\right),(2)$ Geneva State

127 Forest, Geneva Co., Alabama $\left(31.12^{\circ},-86.17^{\circ}\right)$, (3) Historic Blakeley State Park, Baldwin Co., 128 Alabama $\left(30.74^{\circ},-87.91^{\circ}\right)$, (4) Saint Francis National Forest, Lee Co., Arkansas $\left(34.71^{\circ},-90.73^{\circ}\right)$,

129 (5) Edgar Evins State Park, Dekalb Co., Tennessee $\left(36.08^{\circ},-85.83^{\circ}\right)$, and (6) Standing Stone State 
130 Park, Overton Co., Tennessee $\left(36.47^{\circ},-85.42^{\circ}\right.$ ) (all coordinates in WGS84). Sites 1, 2, and 3 were

131 first invaded by fire ants approximately 74, 55, and 82 years ago, respectively, while sites 4,5 ,

132 and 6 have not been invaded by fire ants (Callcott \& Collins, 1996). All sites are characterized by

133 temperate mixed forests and abundant edge and disturbed habitats where both fence lizards

134 and fire ants are found at their highest densities (Langkilde, 2009b; Langkilde, unpublished

135 data). Only adult fence lizards were collected for behavioural trials, as juvenile lizards flee from

136 fire ant attack at high rates regardless of population of origin (Langkilde, 2009a). Following

137 capture, lizards were measured for mass (to the nearest g) and snout-vent length (SVL, to the

138 nearest $\mathrm{mm}$ ). They were housed in mixed sex groups (3-4 lizards) in plastic enclosures (56 X 40

139 X $30 \mathrm{~cm}, \mathrm{~L}$ X W X H) furnished with a water dish and shelter. A 60-W incandescent lamp at one

140 end of the enclosure created a thermal gradient allowing lizards to thermoregulate. Lizards

141 were provided water ad libitum and fed crickets (Acheta domesticus) dusted with

142 supplementary minerals and vitamins four times weekly (Herptivite and Ultrafine Calcium with

143 Vitamin D; Repcal, Los Gatos, CA).

$144 \quad$ We used these lizards to test whether the difference in behavioural response to fire ants

145 following invasion is generalized to native species - ants that provide similar stimuli to fire ants

146 but not do not pose a lethal threat (Buschinger \& Maschwitz, 1984; Wilson, 2003; Thawley,

147 personal observation), and a native avian predator to which lizards should generally respond by

148 maintaining crypsis (Parker, 1994).

149 Behavioural Response to Ants

150 We tested lizards from invaded $(n=55)$ and uninvaded sites $(n=43)$ for their fleeing

151 response to fire ants and two species of native ants (Dorymyrmex sp. and Pheidole sp.) that 
152 serve as food for fence lizards between 2011 and 2014. While these native ants will recruit to

153 lizards, they have lower densities, recruit less aggressively, and have less potent venom than

154 fire ants (or lack venom altogether), resulting in lower danger to fence lizards (Wilson, 2003;

155 Tschinkel, 2006). Behavioural tests followed a protocol described in Langkilde (2009a). Briefly,

156 we tethered lizards to pegs with $1 \mathrm{~m}$ lengths of cotton thread tied loosely around their necks.

157 Pegs were placed in the ground $30 \mathrm{~cm}$ from a target ant mound, allowing the lizard to flee from

158 ant attack but preventing escape into the surrounding landscape. Temperature of mounds and

159 lizards was determined using a Raytek MT-6 infrared thermometer (Raytek Corporation, Santa

160 Cruz, California, USA) accurate to $\pm 0.2^{\circ} \mathrm{C}$. Target mounds were gently disturbed to bring ants to

161 the surface, and lizards were placed onto undisturbed portions of focal mounds such that

162 disturbed ants could find lizards. Trials ended after 60 seconds or when a lizard fled beyond the

163 boundary of the ant mound. We recorded the time at which the lizard fled from the mound and

164 the average number of ants on the lizard. All lizards were tested against all three ant species on

165 consecutive days, with the order of ant species being randomized.

We analyzed the flight response of lizards to the three species of ant using a generalized

167 linear mixed model with a logit link. Our initial model included invasion status (invaded or

168 uninvaded), sex, treatment (ant species), trial order, year, and interactions (invasion

169 status*treatment, invasion status*sex, and invasion status*order) as fixed effects; site nested

170 within invasion status as a random effect; snout-vent-length (SVL), mass, lizard temperature,

171 mound temperature, and number of attacking ants as covariates; and a random effect for

172 individual identity to account for repeated measures from individual lizards. Our final model

173 included invasion status, sex, ant species, and trial order as fixed effects; site nested within 
174 invasion status as a random effect; and SVL and lizard temperature as covariates. Year,

175 interactions between fixed effects, mass, mound temperature, and number of attacking ants

176 did not significantly explain variation in the behavioural response of lizards and were omitted

177 from the final model. Satterthwaite's Approximation was used to determine denominator

178 degrees of freedom for F-tests (Keselman, Algina, Kowalchuk, \& Wolfinger, 1999).

179 Behavioural Response to an Avian Predator:

180 We filmed behavioural responses of lizards from three fire ant invaded sites $(n=59)$ and

181 three sites uninvaded by fire ants $(n=41)$ to a simulated avian attack in an experimental arena in

182 2013. The arena ( $56 \times 40 \times 30 \mathrm{~cm}, \mathrm{~L} \times \mathrm{W}$ X H) was furnished with a sand substrate and a hollow,

183 half-log shelter in the center of the arena which lizards could perch on and seek refuge

184 beneath. We used a preserved adult American Kestrel on loan from the Penn State

185 Ornithological Collection as a predator model (Federal Salvage Permit MB028785-0; PA Permit

186 SAL00436). American Kestrels (Falco sparverius) are common, native predators of sceloporine

187 lizards (Knowlton \& Stanford, 1942; Craig \& Trost, 1979), and have been used in antipredator

188 behavioural studies with sceloporine lizards (Fine, 1999). The preserved kestrel was positioned

189 in an attack posture with wings slightly spread, and we attached realistic cardboard eyes to

190 better simulate a living predator, as lizards use the appearance of eyes to gauge the danger

191 presented by a predator (Hennig, 1977). The kestrel bore an inconspicuous wire harness

192 attached to a fixture on the ceiling directly above the test arena with clear monofilament line.

193 This allowed a clearance of $10 \mathrm{~cm}$ between the kestrel and the top of the lizard's perch site in

194 the experimental arena. Pilot data revealed that this setup produced a behavioural response in 
$195 \approx 50 \%$ of focal lizards. A blind hid observers throughout the trials and hid the kestrel from the 196 focal lizard prior to a simulated attack.

197 Each day we randomly selected an untested lizard from each housing enclosure for

198 testing to prevent stress associated with prior lizard handling in the same enclosure from

199 influencing results. Each lizard was tested once. All trials were conducted within one minute of

200 first handling the focal lizard to ensure that elevated stress due to handling did not affect

201 responses (Romero \& Reed, 2005). To commence a behavioural trial, we measured the focal

202 lizard's temperature as described previously and placed it in the experimental arena. We

203 standardized each focal lizard's position by placing it lengthwise on the perch, facing the

204 direction from which the predator would appear and ensuring that all four feet were in contact

205 with the perch. We then retreated behind the blind and released the kestrel. The kestrel passed

206 over the perch four times (twice from each direction).

207 We recorded trials using a small webcam positioned within the blind and connected to a

208 laptop computer. A small light, out of the lizard's visual range, indicated the release of the

209 kestrel and was used to assess time to respond. We used Media Player Classic v1.5.2 (mpc-

210 hc.org) to quantify three behavioural variables for each trial: (1) whether or not a lizard

211 behaviourally responded to the simulated attack, (2) latency to response (time between kestrel

212 release and initiation of a response by the focal lizard), and (3) the strength of the response.

213 Response strength was assigned one of four levels: 0 - no reaction; 1 - weak reaction (the lizard

214 ducked its head or flattened its body to the perch, but did not move more than two of its feet);

2152 - strong reaction (the lizard moved three or more of its feet and substantially shifted its 
216 position, usually onto the side of the half-log, but remained on the perch); and 3 - flight (the

217 lizard completely left the perch, either seeking shelter beneath it or moving onto the substrate).

218 We tested for differences in probability of a lizard responding to simulated avian attack

219 using logistic regression with invasion status (invaded or uninvaded) and sex as fixed effects and

220 SVL and lizard temperature as covariates. For the subset of lizards that did respond to the

221 simulated avian predator $(n=53)$, differences in latency to respond were assessed using a

222 general linear model with invasion status and sex as fixed effects and SVL and lizard

223 temperature as covariates. We tested for differences in strength of response using ordinal

224 logistic regression with invasion status and sex as fixed effects and SVL and lizard temperature

225 as covariates. As latency to respond and strength of response were unrelated (Spearman's rho:

$226-0.126, p>0.373)$, we analyzed these two responses separately.

227 Injury Prevalence

228 We recorded evidence of injury, including missing limbs or parts of limbs, broken or

229 regenerated tails, and scars for lizards, from three fire ant invaded and three fire ant uninvaded

230 sites in 2011-2014 ( $n=589)$. These are the same sites as those from which we obtained the

231 lizards used for behavioural trials. Injuries, including broken or regenerated tails, have been

232 used for lizards as proxies for predation pressure (Arnold, 1988; Parker, 1994; but see Angilletta

233 et al., 2004). We did not consider missing digits as injuries, as digits are lost outside of

234 predatory interactions during intraspecific competition, aggressive courtship, or shedding

235 (Schoener \& Schoener, 1980).

236 We tested for differences in prevalence of injury using a generalized linear mixed model

237 with a logit link with an initial model including invasion status (invaded or uninvaded), sex, 
238 interactions (invasion status* sex and invasion status*SVL), and year as fixed effects, site nested

239 within invasion status as a random effect, and SVL and mass as covariates. Interactions

240 between fixed effects (above) and lizard mass did not significantly explain variation in the data

241 as determined by likelihood ratio tests and were omitted from the final model. This model for

242 injury prevalence thus included invasion status and sex as fixed effects, site nested within

243 invasion status as a random effect, and SVL as a covariate. A model selection approach

244 comparing AICc values of alternative a priori models also resulted in the selection of this same

245 best fit model. All analyses were conducted using SPSS v.21 (IBM Corp., 2012).

246 Ethical Note

247 No lizards were killed during trials or exhibited sublethal effects of exposure to fire ants such as

248 loss of muscle tone or lethargy. Lizards were returned to points of capture where permitted;

249 where release was not permitted, lizards were euthanized and accessioned as specimens at

250 Pennsylvania State University. Animal collection was permitted by the respective states:

251 Alabama (Permit \#'s: 2011000058268680, 2012000086668680, 2013000092668680,

252 2014070574868680); Arkansas (Permit \#'s: SO-FW-FY10-05, SO-FW-FY12-09, 041120111,

253 040420122, 040420133, 051520141), and Tennessee (Permit \#'s: 2010-025, 3574). Research

254 protocols were approved by the animal ethics committees of Pennsylvania State University

255 (Protocol \# 44595 and 35780) and Auburn University (Protocol \# 2011-1922).

256 RESULTS

257 Behavioural Response to Ants

258 Lizards from fire ant uninvaded sites fled less frequently from encounters with native

259 ants and invasive fire ants than did lizards from fire ant invaded sites (Invasion Status: 
$260 \quad \beta_{\text {Uninvaded }}=-1.469, F_{1,4}=13.799, P<0.018 ;$ Fig. $\left.1 \mathrm{~A}\right)$. The odds of lizards from invaded sites fleeing

261 were 4.3 times higher than those from uninvaded sites. Lizards from both invaded and

262 uninvaded sites showed differences in frequency of flee responses to different species of ants

263 (Ant Species: $F_{2,285}=9.111, P<0.001$; Invasion Status*Ant Species: $F_{2,283}=1.484, P>0.229$;

264 interaction not included in final model). Lizards fled less from the Pheidole sp. of ant than from

265 the other two ant species (Ant Species: $\beta_{\text {Pheidole }}=-1.404, P<0.001 ;$ Sex: $F_{1,93}=4.505, P<0.036$; SVL:

$266 \quad F_{1,95}=6.935, P<0.01$; Lizard Temperature: $F_{1,285}=7.522, P<0.006$; Trial Order: $F_{2,285}=3.924$,

$267 P<0.021)$.

268 Behavioural Response to Avian Predators

269 Lizards from fire ant invaded and uninvaded sites were similarly likely to respond to the

270 model avian predator (Fig. 1B), had a similar latency to respond (Fig. 2), and their response was

271 of similar strength (Fig. 3) (Response to avian predator, Invasion Status: Wald $\chi^{2}{ }_{1}=0.027$,

$272 P=0.577 ;$ Sex: Wald $\chi^{2}{ }_{1}=0.038, P=0.845 ;$ SVL: Wald $\chi^{2}{ }_{1}=1.527, P=0.216$; Lizard Temperature:

273 Wald $\chi^{2}{ }_{1}=0.227, P=0.634$ ) (Latency to respond, Invasion Status: $F_{1,51}=0.882, P=0.352$; Sex:

$274 \quad F_{1,51}=0.139, P=0.711 ;$ SVL: $F_{1,51}=0.090, P=0.765$; Lizard Temperature: $F_{1,51}=0.001, P=0.982$ )

275 (Strength of response, Invasion Status: Wald $\chi^{2}{ }_{1}=0.027, P=0.868$; Sex: Wald $\chi^{2}=0.017, P=0.897$;

276 SVL: Wald $\chi^{2}{ }_{1}=0.188, P=0.665$; Lizard Temperature: Wald $\left.\chi^{2}{ }_{1}=0.059, P=0.809\right)$.

277 Injury Prevalence

278 Lizards from fire ant uninvaded sites had lower injury prevalence than did lizards from

279 invaded sites (Invasion Status: $\beta_{\text {Uninvaded }}=-0.778, F_{1,585}=13.799, P<0.001 ;$ Sex: $\beta_{q}=-0.911$,

$280 \quad F_{1,585}=19.718, P<0.001 ; S V L: \beta_{S V L}=0.607, F_{1,585}=13.166, P<0.001 ;$ Fig. 4$)$. 


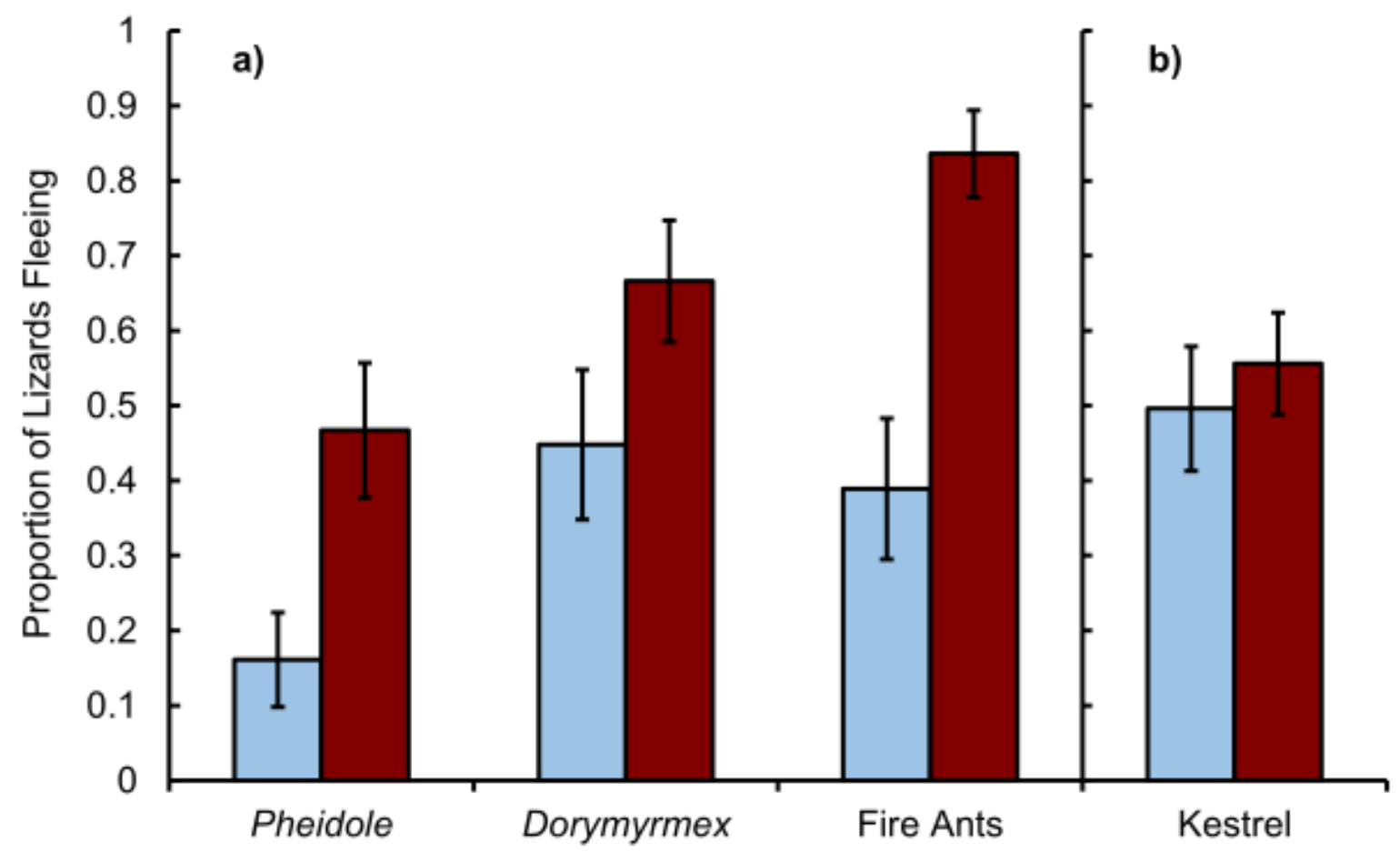

282

283 Fig. 1 Percent of eastern fence lizards (Sceloporus undulatus) from fire ant invaded (dark red)

284 and uninvaded (light blue) populations that fled from a) attack by two genera of native ants and

285 invasive fire ants (estimated marginal means calculated for $\mathrm{SVL}=6.4 \mathrm{~cm}$ and lizard temperature

$286=30.7^{\circ} \mathrm{C}$ ) and $\mathrm{b}$ ) simulated attacks by an avian predator (estimated marginal means calculated

287 for $\mathrm{SVL}=6.5 \mathrm{~cm}$ and lizard temperature $=33^{\circ} \mathrm{C}$ ). Bars represent means \pm 1 standard error. 


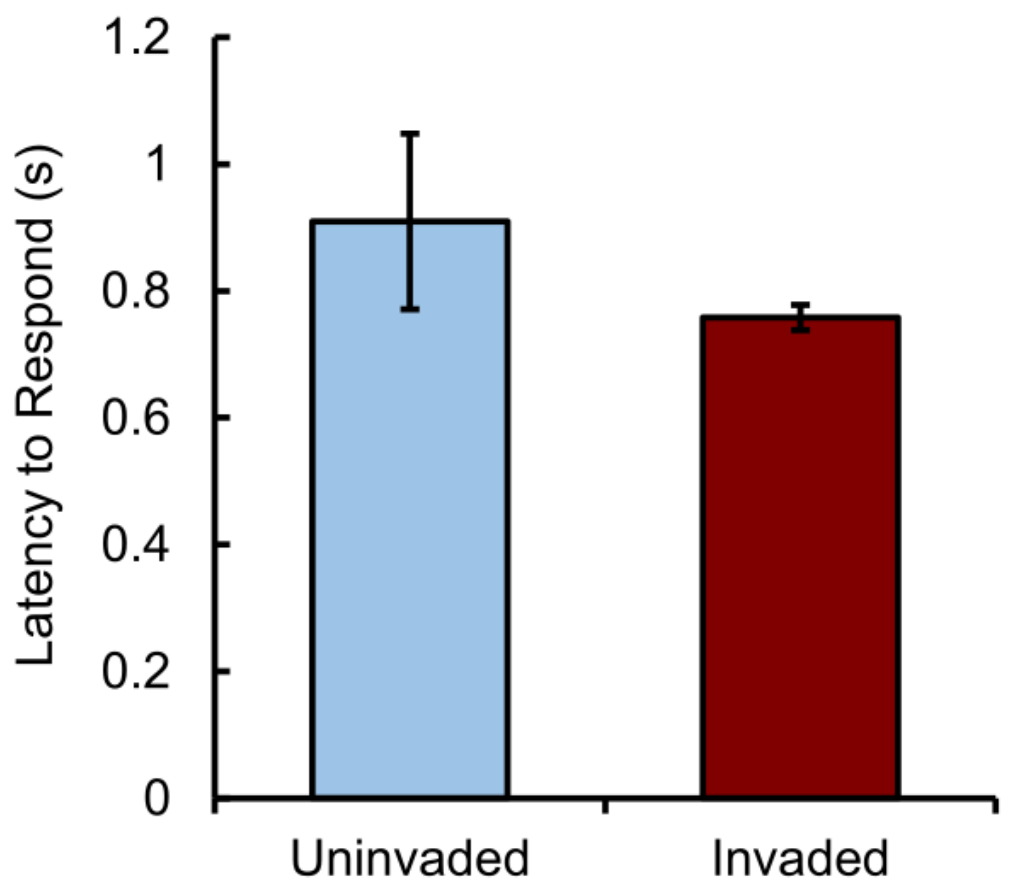

293 Fig. 2 Latency of eastern fence lizards from fire ant uninvaded (light blue) and invaded (dark

294 red) sites to respond to simulated attack by a model Kestrel, an avian predator of this species.

295 Estimated marginal means calculated for $\mathrm{SVL}=6.6 \mathrm{~cm}$ and lizard temperature $=32.7^{\circ} \mathrm{C}$. Bars

296 represent means \pm 1 standard error.

297

298

299

300

301

302

303

304 


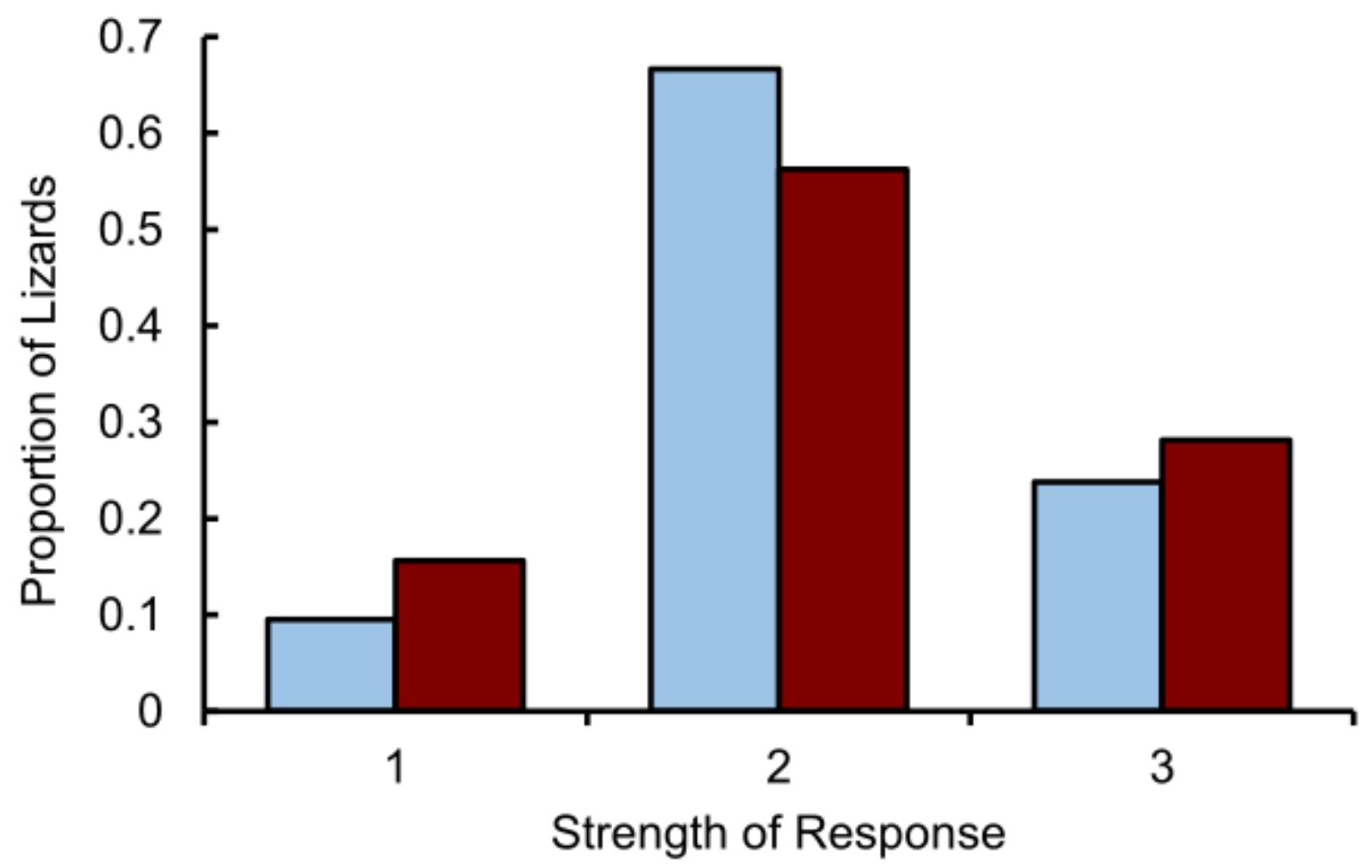

306

307 Fig. 3 Proportion of fence lizards from fire ant uninvaded (light blue; $n=21$ ) and invaded (dark 308 red; $n=32$ ) populations responding to simulated avian attack with weak (1), moderate (2), and 309 strong (3) escape behaviours (see text for a description of behaviours). 


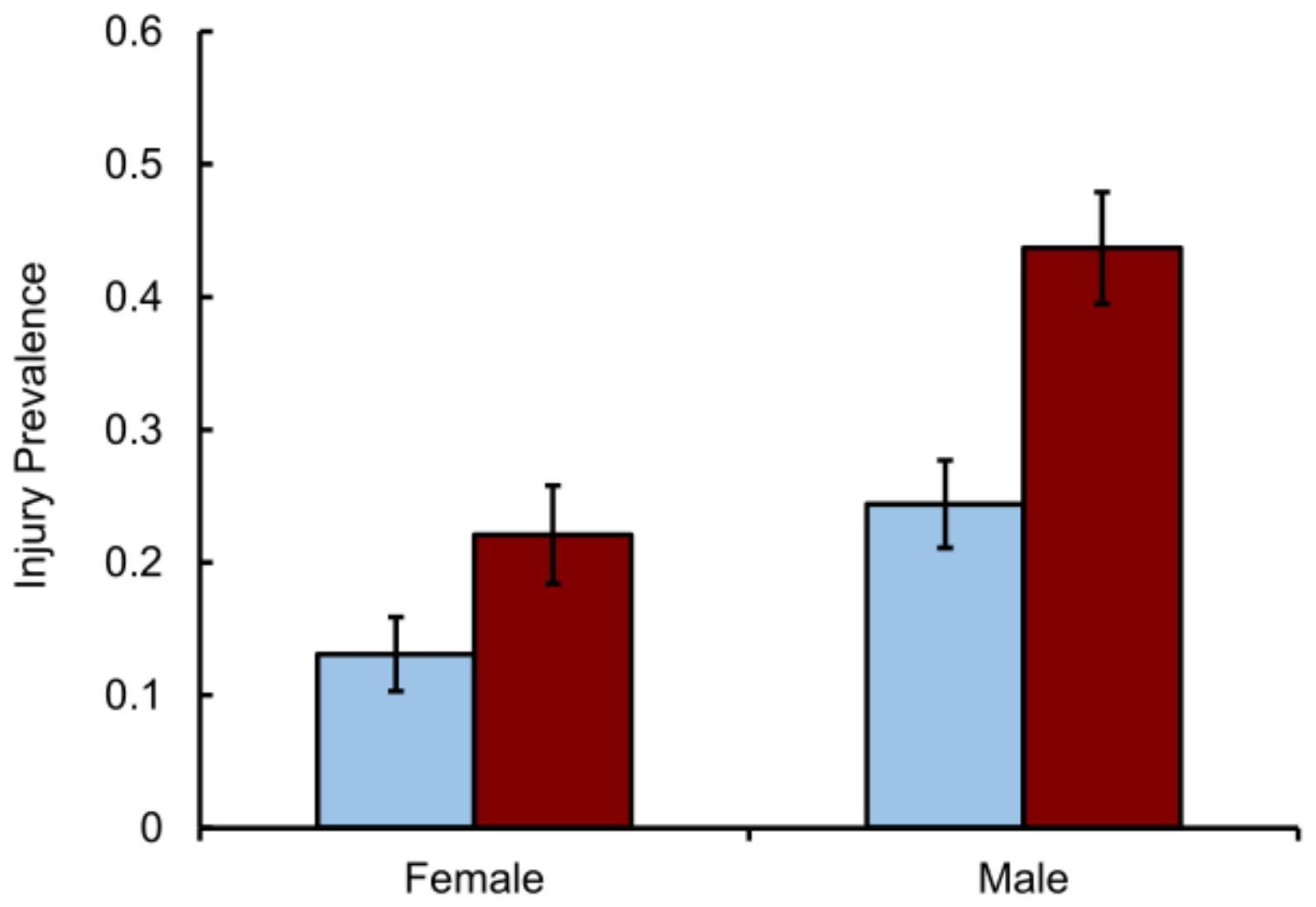

312 Fig. 4 Proportion of female and male fence lizards from fire ant uninvaded (light blue) and

313 invaded (dark red) populations exhibiting injuries. Estimated marginal means calculated for SVL

$314=6.4 \mathrm{~cm}$. Bars represent means \pm 1 standard error . 


\section{DISCUSSION}

The results of this study reveal that the increased use of fleeing behaviour by fence

324 lizards following the invasion of fire ants is not restricted to encounters with this invader, but

325 rather is generalized to native ants. This altered responsiveness is not extended, however, to

326 encounters with avian predators. Higher injury prevalence in lizards from fire ant invaded sites

327 suggests that lizards may suffer increased predation attempts as a cost of this behavioural shift,

328 though the exact cause of this difference is not known.

329 These results extend findings that fence lizards from fire ant invaded sites flee from fire

330 ants at a higher rate than do lizards from uninvaded sites (Langkilde, 2009a; Freidenfelds et al.,

3312012 ) by showing that these invaded site lizards are also more likely to flee from native ants

332 (Fig. 1A). Despite the lesser threat posed by native ants, lizards from populations exposed to

333 fire ants show an increased rate of fleeing from all three ant species included in our trials,

334 suggesting that this response is generalized at least to ants. This generalization could be due to

335 the sensory cues lizards use to respond to ants. Visual diagnosis of ant species can be difficult

336 even for humans (Ward, 2010), and fence lizards have been observed consuming fire ants on

337 their mounds when ant activity is low (Long, 2013), despite potentially lethal consequences

338 (Robbins \& Langkilde, 2012). However, these lizards often initiate flight after ants crawl on their

339 bodies even without being stung (Thawley, personal observation), suggesting that lizards may

340 respond to tactile cues that are present when ants defend their mounds. Like visual cues, these

341 tactile cues are likely similar across ant species.

342 If lizards cannot reliably distinguish fire ants from native ants before being stung, fleeing

343 from all species of ant may be the only behavioural strategy currently available to these lizards 
344 to ensure they avoid fire ant envenomation. However, fewer lizards fled from one of the native 345 ant species (Pheidole sp.; Fig. 1A), suggesting that they may be able to distinguish between ant 346 species under some conditions. It is possible that different ant species vary in the amount of

347 cue they provide (e.g., more or less of the same tactile contact), allowing differential responses

348 by lizards. Fence lizards from fire ant invaded sites, but not uninvaded sites, avoid the scent of

349 fire ants (Langkilde, 2009b), suggesting that fence lizards possess at least one pathway allowing 350 identification of fire ants. If fence lizards can use relevant cues to discriminate fire ants from

351 native ants, future adaptation may allow differential behavioural responses to different species 352 of ants (Sih, Ferrari, \& Harris, 2011).

353 In contrast to the generalization of behaviours across ant species, we found no evidence 354 that the differences in behavioural response to ants between lizards from invaded versus 355 uninvaded sites are generalized to avian predators (Figs. 1B,2,3). Lizards have a long 356 evolutionary history with native avian predators, which pose a threat to lizards regardless of 357 fire ant presence. Birds are ecologically distinct from ants and provide different cues, which 358 may facilitate differential behavioural responses. Further research on what cues (tactile, visual, 359 chemosensory) lizards use to detect predators would shed light on how they may evaluate 360 avian and ant predators (e.g., Cantwell \& Forrest, 2013) or distinguish between dangerous and 361 non-threatening animals, including ants (see Suarez, Jon, \& Case, 2000 for an example of a 362 lizard distinguishing between ant species).

363 The generalized behavioural response to ants we observed is likely beneficial on 364 average. In fire ant invaded areas, fence lizards encounter fire ants frequently due to their high 365 relative abundance (Morrison, 2002; Freidenfelds et al., 2012). In these interactions, 
366 misidentifying a fire ant as a native ant could be lethal, and fleeing from all ants as if they were

367 fire ants is likely an adaptive strategy (Freidenfelds et al., 2012). However, fleeing breaks

368 crypsis, a common defense to decrease detection by visual predators (Lima \& Dill, 1990).

369 Lizards that behaviourally respond to ants may thus risk predation by visual predators; a

370 survival cost that has been suggested for other species interacting with invasive fire ants (Allen,

371 Demarais, \& Lutz., 1997; Long, Conner, Smith, \& McCleery, 2015).

372 Our field data suggest a predation cost to this anti-ant behaviour as lizards at invaded

373 sites show higher prevalence of injuries. The fact that males exhibit higher injury prevalence

374 than females supports the interpretation of injury prevalence as reflecting predation attempts.

375 Males select perch sites that improve territorial defence and courtship opportunities (Pounds \&

376 Jackson, 1983; Thawley, personal observation) but likely expose them to greater predation risk

377 (Parker, 1994). Injury can itself increase risk of mortality and, in the case of tail loss, result in

378 greater vulnerability to predators (Wilson, 1992; Downes \& Shine, 2001), increasing potential

379 fitness costs. The observed pattern of greater injury prevalence in fire ant invaded sites may be

380 due to increased responsiveness to ants, or to a change in the behavioural response of these

381 lizards to stress. Lizards from fire ant invaded sites are less likely to seek refuge underneath

382 cover objects when stressed in the lab, a strategy that may help them avoid attack by fire ants

383 at a cost of increased exposure to native predators (Trompeter \& Langkilde, 2011).

384 It is important to note that the observed differences in injury prevalence are

385 observational and could be explained by factors other than lizard behavioural differences.

386 Increased injury prevalence at fire ant invaded sites could reflect a greater diversity or absolute

387 abundance of predators in southern regions (Pianka, 1970). While we lack data on abundances 
388 of native predators at study sites, habitats at these sites are ecologically similar and should

389 share similar predator communities (Langkilde 2009a). Additionally,, lizard populations farther

390 north than those at the study sites do not show lower injury prevalence (Thawley, unpublished

391 data), arguing against a latitudinal cline in predation pressure in this instance (e.g., Pianka,

392 1970). Alternatively, this pattern could result from higher survival of predatory attacks by

393 lizards at fire ant invaded sites resulting in higher rates of injury. We consider this possibility

394 unlikely, however, as lizards from all sites flee from avian predators at similar rates (Fig. 1B) and

395 with similar strengths and latencies to react (Figs. 2 and 3).

Together, these data suggest that this generalized behavioural reaction to ants may be

397 maladaptive in the presence of native ants. Maladaptation due to biological invasions may be

398 common, as previously adaptive responses to native species can reduce fitness when employed

399 against invaders (Schlaepfer et al. 2002; Schlaepfer et al., 2005; Sih 2013). In this case, fleeing

400 from fire ants is an effective defence and should improve lizard survival and fitness, even in the

401 presence of native predators (Freidenfelds et al., 2012). However, because lizards that are

402 adapted to fire ants generalize flight responses to non-lethal native ants, they likely experience

403 increased attacks by visual predators, increased energy expenditure, lost feeding opportunities

404 by fleeing from potential prey (native ants), and reduced ability to defend territories (Lima \&

405 Dill, 1990; Parker, 1994; Mobley, 1998). Future adaptations may support more optimal

406 behavioral responses, such as fleeing only from dangerous ants, as selection should favor the

407 incorporation of new cues or other refinements of generalized behavioural rules that promote

408 higher fitness (Schlaepfer et al., 2010). 
Future research into changes in behaviour triggered by novel threats should not only

410 document the existence of responses to these pressures, but also assess whether these

411 adaptations are generalized to other contexts. Some research suggests that generalized

412 adaptations may better allow for adaptive responses to novel conditions when compared to

413 more specific adaptations, which may be inappropriate or ineffective in novel situations

414 (Carthey \& Banks, 2014, but see Sih, 2013). However, our research shows that generalized

415 adaptations are also vulnerable to being maladaptive under some types of rapid environmental

416 change. Indeed, as anthropogenic change accelerates, disentangling the multiple drivers of

417 behavioural and other adaptations, as well as assessing their costs and benefits, is likely to

418 become increasingly challenging (Caro \& Sherman, 2011). Understanding whether novel

419 adaptations are generalized to multiple contexts will be critical for determining the long-term

420 consequences of adaptive responses to environmental change and for managing affected

421 species.

422

\section{REFERENCES:}

424 Abrams, P. A. (2000). The evolution of predator-prey interactions: theory and evidence. Annual 425 Review of Ecology and Systematics, 31, 79-105. doi: 10.2307/221726

426 Allen, C. R., Demarais, S., \& Lutz, R. S. (1994). Red imported fire ant impact on wildlife: an 427 overview. The Texas Journal of Science, 46(1), 51-59.

428 Allen, C. R., Demarais, S., \& Lutz, R. S. (1997). Effects of red imported fire ants on recruitment of 429 white-tailed deer fawns. Journal of Wildlife Management, 61(3), 911-916. 
430 Arak, A. (1983). Male-male competition and mate choice in anuran amphibians. In P. Bateson (Ed.), Mate Choice (pp. 181-210). Cambridge, UK: Cambridge University Press.

Arnold, E. N. (1988). Caudal autotomy as a defense. In C. Gans \& R. B. Huey (Eds.), Biology of the Reptilia (Vol. 16, pp. 235-274). New York, New York, USA: Alan R. Liss.

434 Bradley St. Clair, J., \& Howe, G. T. (2007). Genetic maladaptation of coastal Douglas-fir seedlings to future climates. Global Change Biology, 13, 1441-1454. doi: 10.1111/j.1365-

Buschinger, A., \& Maschwitz, U. (1984). Defensive behavior and defensive mechanisms in ants. In H. R. Hermann (Ed.), Defensive mechanisms in social insects. New York, NY, USA: Praeger.

Callcott, A. A., \& Collins, H. L. (1996). Invasion and range expansion of imported fire ants (Hymenoptera: Formicidae) in North America from 1918-1995. The Florida Entomologist, 79(2), 240-251. doi: 10.2307/3495821

Cantwell, L. R., \& Forrest, T. G. (2013). Response of Anolis sagrei to acoustic calls from predatory and nonpredatory birds. Journal of Herpetology, 47(2), 293-298. doi:

446 Carlile, P. A., Peters, R. A., \& Evans, C. S. (2006). Detection of a looming stimulus by the Jacky dragon: selective sensitivity to characteristics of an aerial predator. Animal Behaviour, 72, 553-562. doi: 10.1016/j.anbehav.2005.10.027

449 Caro, T., \& Sherman, P. W. (2011). Endangered species and a threatened discipline: behavioural ecology. Trends in Ecology \& Evolution, 26(3), 111-118. doi: 10.1016/j.tree.2010.12.008 
451 Carthey, A. J. R., \& Banks, P. B. (2014). Naïveté in novel ecological interactions: lessons from theory and experimental evidence. Biological Reviews, 89(4), 932-949. doi: 10.1111/brv.12087

DeMarco, V. G., Drenner, R. W., \& Ferguson, G. W. (1985). Maximum prey size of an

Cooper Jr., W. E., Burghardt, G. M., \& Brown, W. S. (2000). Behavioural responses by hatchling

Conant, R., \& Collins, J. T. (1998). A field guide to reptiles \& amphibians of eastern and central North America (Third ed.). Boston: Houghton Mifflin. racers (Coluber constrictor) from two geographically distinct populations to chemical stimuli from potential prey and predators. Amphibia-Reptilia, 21, 103-115. doi: $10.1163 / 156853800507318$

Craig, T. H., \& Trost, C. H. (1979). The biology and nesting density of breeding American Kestrels and Long-Eared Owls on the Big Lost River, southeastern Idaho. The Wilson Bulletin, $91(1), 50-61$.

Crespi, B. J. (2000). The evolution of maladaptation. Heredity, 84(6), 623-629. doi: 10.1046/j.1365-2540.2000.00746.x insectivorous lizard, Sceloporus undulatus garmani. Copeia, 1985(4), 1077-1080. doi: $10.2307 / 1445269$

Downes, S., \& Shine, R. (2001). Why does tail loss increase a lizard's later vulnerability to snake predators? Ecology, 82(5), 1293-1303. doi: 10.2307/2679990 southern Mississippi. The American Midland Naturalist, 163(1), 54-63. doi: 10.1674/0003-0031-163.1.54 
473 Fine, P. V. A. (1999). Aerial predator recognition by free-ranging Sceloporus occidentalis. Journal of Herpetology, 33(1), 128-131. doi: 10.2307/1565553

475 Freidenfelds, N. A., Robbins, T. R., \& Langkilde, T. (2012). Evading invaders: the effectiveness of a behavioral response acquired through lifetime exposure. Behavioral Ecology, 23, 659-

Frid, A., \& Dill, L. M. (2002). Human-caused disturbance stimuli as a form of predation risk. Conservation Ecology, 6(1), 11.

Gröning, J., \& Hochkirch, A. (2008). Reproductive interference between animal species. The

Gwynne, D. T., \& Rentz, D. C. F. (1983). Beetles on the bottle: male buprestids mistake stubbies for females (Coleoptera). Journal of the Australian Entomological Society, 22, 79-80. doi: 10.1111/j.1440-6055.1983.tb01846.x

Heiner, R. A. (1983). The origin of predictable behavior. The American Economic Review, 73(4), 560-595.

Hennig, C. W. (1977). Effects of simulated predation on tonic immobility in Anolis carolinensis: The role of eye contact. Bulletin of the Psychonomic Society, 9(4), 239-242. doi: $10.3758 /$ bf03336987

Jennions, M. D., \& Petrie, M. (1997). Variation in mate choice and mating preferences: a review of causes and consequences. Biological Reviews, 72, 283-327. doi: 10.1111/j.1469185X.1997.tb00015.x

493 Jensen, J. B., Camp, C. D., Gibbons, J. W., \& Elliott, M. J. (Eds.). (2008). Amphibians and reptiles of Georgia. Athens, GA, USA: University of Georgia Press. 
495 Kerby, J. T., \& Post, E. (2013). Advancing plant phenology and reduced herbivore production in a terrestrial system associated with sea ice decline. Nature Communications, 4, 2514. doi: $10.1038 /$ ncomms3514

Keselman, H. J., Algina, J., Kowalchuk, R. K., \& Wolfinger, R. D. (1999). The analysis of repeated measurements: a comparison of mixed-model Satterthwaite F tests and a nonpooled adjusted degrees of freedom multivariate test. Communications in Statistics - Theory and Methods, 28(12), 2967-2999. doi: 10.1080/03610929908832460

Kiesecker, J. M., \& Blaustein, A. R. (1997). Population differences in responses of Red-Legged frogs (Rana aurora) to introduced bullfrogs. Ecology, 78(6), 1752-1760. doi: $10.2307 / 2266098$

Knowlton, G. F., \& Stanford, J. S. (1942). Reptiles eaten by birds. Copeia, 1942(3), 186. doi: $10.2307 / 1438225$

Langkilde, T. (2009). Holding ground in the face of invasion: native fence lizards (Sceloporus undulatus) do not alter their habitat use in response to introduced fire ants (Solenopsis invicta). Canadian Journal of Zoology, 87, 626-634. doi: 10.1139/Z09-053

512 Langkilde, T., \& Freidenfelds, N. A. (2010). Consequences of envenomation: red imported fire ants have delayed effects on survival but not growth of native fence lizards. Wildlife Research, 37, 566-573. doi: 10.1071/WR10098 and prospectus. Canadian Journal of Zoology, 68(4), 619-640. doi: 10.1139/z90-092 
517 Long, A. K. (2013). Sceloporus undulatus (Eastern fence lizard). Feeding behavior. Herpetological $518 \quad$ Review, 44(3):513-514.

519 Long, A. K., Conner, L. M., Smith, L. L., \& McCleery, R. A. (2015). Effects of an invasive ant and

Marco, A., Kiesecker, J. M., Chivers, D. P., \& Blaustein, A. R. (1998). Sex recognition and mate choice by male western toads, Bufo boreas. Animal Behaviour, 55(6), 1631-1635. doi:

Orr, H. A. (2000). Adaptation and the cost of complexity. Evolution, 54(1), 13-20. doi:

Mobley, E. R. (1998). A base line population study of the southern fence lizard, Sceloporus undulatus undulatus, in central Florida. MS, University of Central Florida, Orlando, FL.

Morrison, L. W. (2002). Long-term impacts of an arthropod-community invasion by the

Meshaka Jr., W. E. (1996). Anuran Davian behavior: a Darwinian dilemma. Florida Scientist, $59(2), 74-75$.

Martín, J., Luque-Larena, J. J., \& Lopez, P. (2009). When to run from an ambush predator: balancing crypsis benefits with costs of fleeing in lizards. Animal Behaviour, 78(4), 10111018. doi: http://dx.doi.org/10.1016/j.anbehav.2009.07.026 imported fire ant, Solenopsis invicta. Ecology, 83(8), 2337-2345. doi: 10.1890/00129658(2002)083[2337:LTIOAA]2.0.CO;2 10.1111/j.0014-3820.2000.tb00002.x

Parker, W. S. (1994). Demography of the fence lizard, Sceloporus undulatus, in northern Mississippi. Copeia, 1994(1), 136-152. doi: 10.2307/1446680 
539 Payne, R. B. (1998). Brood parasitism in birds: strangers in the nest. Bioscience, 48(5), 377-386.

540 Pianka, E. R. (1970). Comparative autecology of the lizard Cnemidophorus tigris in different 541 parts of its geographic range. Ecology, 51(4), 703-720. doi: 10.2307/1934053

542 Pounds, J. A., \& Jackson, J. F. (1983). Utilization of perch sites by sex and size classes of 543 Sceloporus undulatus undulatus. Journal of Herpetology, 17(3), 287-289. doi:

$544 \quad 10.2307 / 1563836$

545 Robbins, T. R., \& Langkilde, T. (2012). The consequences of lifetime and evolutionary exposure to toxic prey: changes in avoidance behavior through ontogeny. Journal of Evolutionary Biology, 25, 1937-1946.

548 Romero, L. M., \& Reed, J. M. (2005). Collecting baseline corticosterone samples in the field: is under 3 min good enough? Comparative Biochemistry and Physiology Part A: Molecular \& Integrative Physiology, 140(1), 73-79. doi: http://dx.doi.org/10.1016/j.cbpb.2004.11.004

552 Schlaepfer, M. A., Runge, M. C., \& Sherman, P. W. (2002). Ecological and evolutionary traps. Trends in Ecology and Evolution, 17(10), 474-480. doi: 10.1016/S0169-5347(02)02580-6

554 Schlaepfer, M. A., Sherman, P. W., Blossey, B., \& Runge, M. C. (2005). Introduced species as 555 evolutionary traps. Ecology Letters, 8(3), 241-246. doi: 10.1111/j.1461-

557 Schlaepfer, M. A., Sherman, P. W., \& Runge, M. C. (2010). Decision making, environmental 558 change, and population persistence. In D. F. Westneat \& C. W. Fox (Eds.), Evolutionary behavioral ecology (pp. 506-515). Oxford: Oxford University Press. 
560 Schoener, T. W., \& Schoener, A. (1980). Ecological and demographic correlates of injury rates in some Bahamian Anolis lizards. Copeia, 1980(4), 839-850. doi: 10.2307/1444463

562 Shine, R. (2010). The ecological impact of invasive cane toads (Bufo marinus) in Australia.

563 Quarterly Review of Biology, 85(3), 253-291. doi: 10.1086/655116

564 Sih, A. (2013). Understanding variation in behavioural responses to human-induced rapid environmental change: a conceptual overview. Animal Behaviour, 85(5), 1077-1088. doi: http://dx.doi.org/10.1016/j.anbehav.2013.02.017

Sih, A., Ferrari, M. C. O., \& Harris, D. J. (2011). Evolution and behavioural responses to humaninduced rapid environmental change. Evolutionary Applications, 4(2), 367-387. doi: 10.1111/j.1752-4571.2010.00166.x

Sinervo, B., Méndez-de-la-Cruz, F., Miles, D. B., Heulin, B., Bastiaans, E., Villagrán-Santa Cruz, M. (2010). Erosion of lizard diversity by climate change and altered thermal niches. Science,

Suarez, A. V., Jon, Q. R., \& Case, T. J. (2000). Prey selection in horned lizards following the 328(5980), 894-899. doi: 10.1126/science.1184695 invasion of Argentine ants in southern California. Ecological Applications, 10(3), 711725. doi: $10.2307 / 2641040$ doi: 10.1016/j.yhbeh.2011.04.001

579 Tschinkel, W. R. (2006). The fire ants. Cambridge, MA: Belknap Press 
580 Vinson, S. B. (1994). Impact of the invasion of Solenopsis invicta (Buren) on native food webs. In D. F. Williams (Ed.), Exotic ants: Biology, impact and control of introduced species (pp. 240-258). Boulder: Westview Press.

583 Ward, P. S. (2010). Taxonomy, phylogenetics, and evolution. In L. Lach, C. Parr \& K. Abbott (Eds.), Ant ecology (pp. 3-17). Oxford: Oxford University Press.

585 Wilson, B. S. (1992). Tail injuries increase the risk of mortality in free-living lizards (Uta stansburiana). Oecologia, 92(1), 145-152. doi: 10.1007/bf00317275

587 Wilson, E. O. (2003). Pheidole in the new world: A dominant, hyperdiverse ant genus. Cambridge, MA, USA: Harvard University Press.

589 Wojcik, D. P., Allen, C. R., Brenner, R. J., Forys, E. A., Jouvenaz, D. P., \& Lutz, R. S. (2001). Red imported fire ants: Impact on biodiversity. American Entomologist, 47(1), 16-23. doi: 


\section{ACKNOWLEDGEMENTS}

We thank E. Baron, D. Ensminger, N. Freidenfelds, S. McGinley, and T. Robbins for assistance with behavioural trials, S. Graham, M. Herr, and G. McCormick for help catching lizards, B. Chitterlings for constructive feedback on prior drafts, T. Robbins for advice on avian trials, M. Brittingham for access to the kestrel specimen, and the staff at Solon Dixon Forestry Education Center, Conecuh and St. Francis National Forests, Historic Blakeley State Park, Geneva State Forests, and Edgar Evins and Standing Stone State Parks. Funding was provided in part by the National Science Foundation (DEB-0949483 to TL). 